\title{
Dayung Context in Fraction
}

\author{
Marhamah Fajriyah N, Ratu Ilma Indra Putri, Zulkardi \\ Universitas Sriwijaya \\ Palembang South Sumatera, Indonesia \\ nasution_marhamah@yahoo.co.id,
}

\begin{abstract}
The students face often difficulties in understanding fraction lesson. It is because the students never get learning basic concept of fraction. This research aimed to get learning trajectory that can help students understand the addition and subtraction of fraction by using dayung context in Asian Games. The research subjects were the six graders of MIN 2 Palembang. The research method that used was design research with three phases, namely preparing for the experiment, the design experiment, and retrospective analysis. However, in this research, the step of the design experiment was until the pilot experiment. The data were the collected by using video recording and photos when doing discussion with the teacher, pilot experiment, written test, observation and interview during the learning process with the students as the subjects in this research. Hypothetical learning trajectory (HLT) designed is compassed to Actual Learning Trajectory (ALT) or students' answers when doing pilot experiment. Based on retrospective analysis and teachers discussion, the learning trajectory is rerevised to be held in the next step of teaching experiment, Moreover the use of dayung can enlarge the students' thought and can make the students understand the addition and fraction subtraction.
\end{abstract}

Keywords-Design Research, Dayung Context, Fraction, Hypothetical Learning Trajectory

\section{INTRODUCTION}

In Indonesia, the curriculum currently applied is the 2013 curriculum. One of the approaches consistent with the 2013 curriculum is PMRI. PMRI is a learning approach adapted from Freudenthal known as Realistic Mathematics Education (RME) and has been developed in Indonesia. Since 2001, PMRI has been widely used in improving the students' interests, attitudes and learning outcomes [1].

PMRI has three main principles, namely Guided reinvention, didactical phenomenology, and Self-developed models [2]. The principle of guided-reinvention in PMRI is aimed at guiding students to re-find mathematical concepts [3]. Didactical principle of phenomenology emphasizes learning by using contextual issues in introducing mathematics to the students [1]. Self-developed model is a bridge between the informal to the formal mathematics.

PMRI is one of the learning approaches that will lead students to understand the math concepts by constructing by themselves through the previous knowledge related to their daily lives, by finding the concept by themselves [4]. This is in line with the statement by Freudenthal that students should be given the opportunity to experience or be directly involved in the learning process [5].
Fractions can be met based on the situations of the same size portion of the whole, the base or part of the groups or can be called as a comparison [6]. Fraction is one of the most complex concepts, but it is needed in students' learning in elementary school [7].

However, in many times, students have difficulties in understanding the fractions material. This is due to the fact that students never receive any knowledge form of the basic concepts of fractions. Students are more likely to be introduced with the use of formulas without involving the concept itself, and the learning is separated from the experience of students' daily lives [8].

Therefore, concrete effort is needed to explore a variety of situations or contexts that are accordance to students' cognitive abilities in mathematics. One of the contexts that can be used is the context which is related to daily life, that is rowing. Mileage of athletes on the start line to finish can present units of a base and able to build students' thinking about the concept of fractions. Besides, the comparison of distance and time to help students in understanding the concept of fractions, and the difference in mileage of athletes build students' thinking about the addition and subtraction of fractions using the model set [9].The use of context in learning mathematics can make a mathematical concept becomes more meaningful because the context may present an abstract mathematical concept in the form of representation that is easy to be understood by students [8].

Previous studies about fraction materials which using PMRI explain that PMRI can help students to understand the concept of fraction used fraction circle. Based on the description above, the problem of this research was: how learning trajectory can help students in making set of models by using the dayung context? The purpose of this study was to produce a learning trajectory that can help students make set of models by using the context of the dayung.

\section{METHODS}

This study used design research. Design research is a systematic study of designing, developing and evaluating the educational interventions (such as programs, strategies and learning materials, products and systems) as solution to solve complex problems in educational practice, which also aims to improve our knowledge of characteristics from those interventions and the process of the design and development [10]. In design research, research implementation process was guided by an instrument called Hypothetical Learning Trajectory (HLT). When learning does not conform to the design that has been designed, it is necessary to be re-designed 
(thought experiment) towards HLT for later re-testing to HLT (instruction experiment). This process takes place continuously depending on the time of doing experiments.

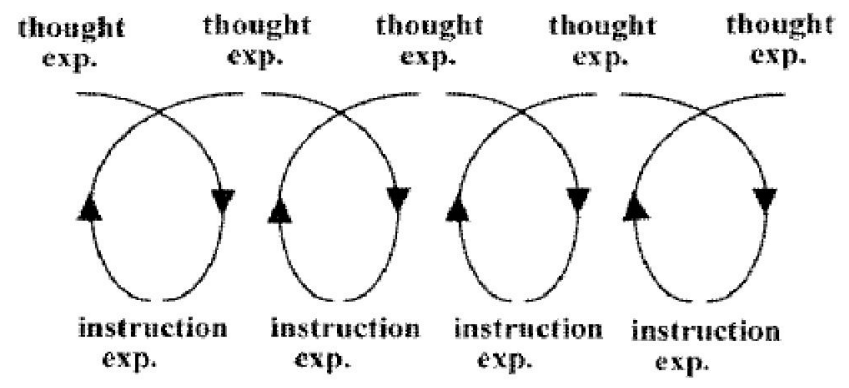

Fig. 1. An iterative process of micro design cycles [11]

There were three stages in the design research, namely: preparing for the experiment, the design experiments, and retrospective analysis [12]. Data collection techniques used were interviews, video recordings and photographs, written tests, observations, and field notes. Through interviews with students, the researchers could ask questions to the students to see whether research objectives by the researchers were achieved. The clinical interview was used as one of the methods to collect the data in this study because it has two main advantages which support the aim of this study. First, it is allowed to make interventions to encourage the students to elaborate on their statement. Second, the clinical interview also provides a continual interaction between inference and observation [13].

\section{RESUlT AND DisCUSSION}

\section{A. Preparing for the Experiment}

The researchers evaluated the literature about the addition and subtraction of fractions materials based on the 2013 curriculum. Lesson plan of the fourth grade in mathematics must stand on its own without having to use Thematic. Linkages the rowing context with the material to be taught, the model set in the addition and subtraction of fractions, the fractions material based on curriculum, PMRI approach, and research design were used in the research method. Furthermore, the researchers discussed together with mathematics teacher who would be a model to learn more about the condition and capabilities of students.

The researchers also discussed the instruments that have been designed consisting of lesson plan (RPP), teacher's guide, students' activity sheets (LAS), pretest and posttest and observation sheets, and adjusted the research schedule with the teacher.

In addition, the researchers also observed the activities of students during the learning process that will be the subject of the research. Observations conducted by the researchers aimed to determine the students' prior ability so that HLT was designed to be more appropriate.

B. The Design Experiment

At this design experiment stage, researcher tested the Hypothetical Learning Trajectory (HLT) that has been
designed.The design experiment stage was divided into two cycles, namely pilot experiment and teaching experiment.

In the pilot of the experiment stage, the researchers only tested the activity sheet that has been designed at the preliminary design stage. At this stage, the researchers acted as the teachers along with six 4th grade students. The names of the students in the pilot experiment stage can be seen in Table 1 .

TABLE I. STUDENTS' NAMES INPILOT EXPERIMENT

\begin{tabular}{|l|l|l|}
\hline No & \multicolumn{1}{|c|}{ Student's Name } & \multicolumn{1}{|c|}{ Ability } \\
\hline 1. & DHY (Student A) & High \\
\hline 2. & SBL (Student B) & High \\
\hline 3. & HAB (Student C) & Medium \\
\hline 4. & RGN (Student D) & Medium \\
\hline 5. & AFN (Student E) & Low \\
\hline 6. & AZA (Student F) & Low \\
\hline
\end{tabular}

The activities in the pilot experiment stage conducted during the first week consisted of three activities: (1) activity lin which students were able to know the elements of the model set, that is the rows and columns that were used to equalize the denominator; (2) activity 2 in which students were expected to add two fractions with different denominators; and (3) activity 3 in which students were asked to write the comparison of the mileage which has been through by athlete in a certain recorded time and students could complete the subtraction of fractions with different denominators.

At this stage, the researchers observed and analyzed about what happened when a series of activities were undertaken in the HLT. Here are description results obtained from trials to students.

In activity 1 , the students were asked to know the factors of compilation model, those were line and colom used to make deminator the same, and to write the problems into their own illustrate. One of students' answer can be seen in Fig. 1.

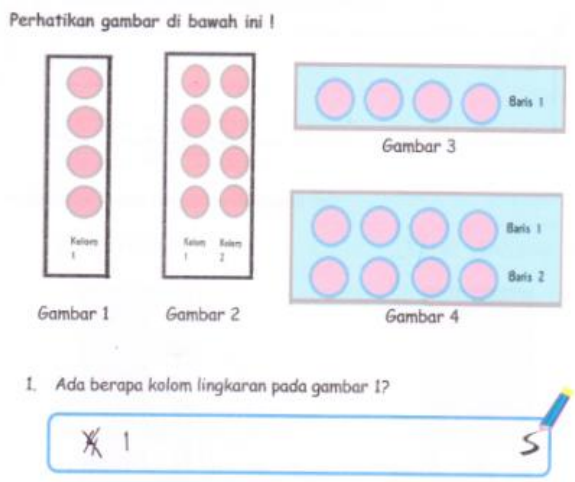

Fig. 2. Students' answer in activity 1

In Fig.2, it can be seen that the students did not understand what the column was. The students only counted the circle, yet they did not count the column. 
Activity 2 in LAS 1 was based on the learning purpose in addition of fraction with different denominator. At first, the students could easily understand the problem in activity 2 , but when they were asked to group the circle in each compilation box based on the instruction given, the students got difficultly in doing it. The students' answer can be seen in Fig.3 as follows:
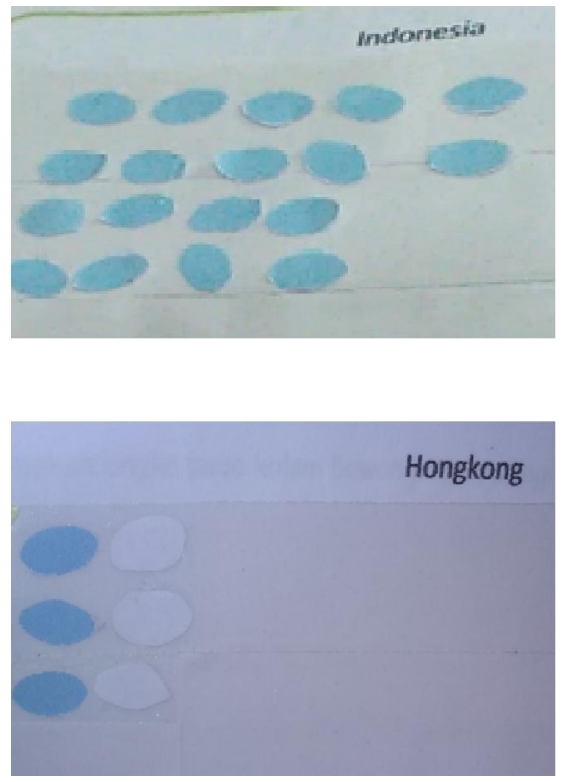

Fig. 3. Students' answer in activity 2

The students' answer in Fig. 3 showed that they knew the number of the column in the blue circle in the compilation box of Indonesia, which was 5 and 1 for Hongkong. However, the students were not careful in understanding the instruction to group the circle that the circle in each compilation box had to be same. It was not suitable with the planned HLT, so it needed HLT correction. After discussing with the teacher as a model, it is concluded that the students have to understand what the line and column were and that it is better that the teacher demonstrate it to show what the line and column.

In activity 3 , the students were able to group the circle in the compilation box. The students were getting more careful in understanding and applying the steps used in grouping the circle in compilation box. It can be seen in the video recorded during the learning process. At first the students made mistake to decide line of the pink circle. Based on the instruction, the number of pink circles was 2 lines, but the students wrote 4 lines. However, after the students were asked to reread the instruction, they realized that their answer was incorrect. For more detail, Fig. 4 below is the students' answer during the learning process.

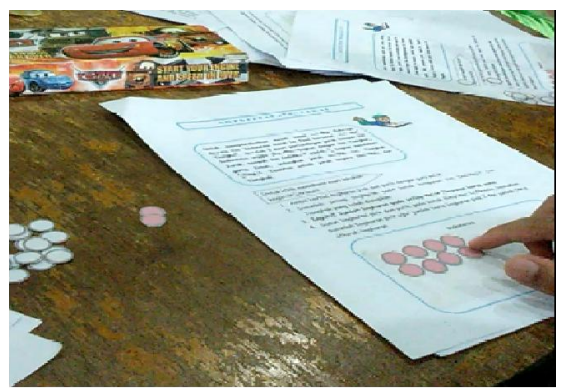

Fig. 4. Students' answer in activity 3

The change of HLT was affected by difficulties that students encountered during the learning process so that students' answers did not correspond to what that the researchers wanted them to achieve. The changes of HLT occurred on the language question on the Students' Activity Sheets, and there were several activities that students needed to add.

At the teaching experiment phase, the revised HLT was tested on 38 students who were the subjects of the research. In the first activity sheet, there were two activities, activity 1 in which students were able to know the elements of the model set, namely the rows and columns used to equalize the denominator, and the activity of both students to add two fractions with different denominators. In the first activity, the students have understood the row and column in the model set.

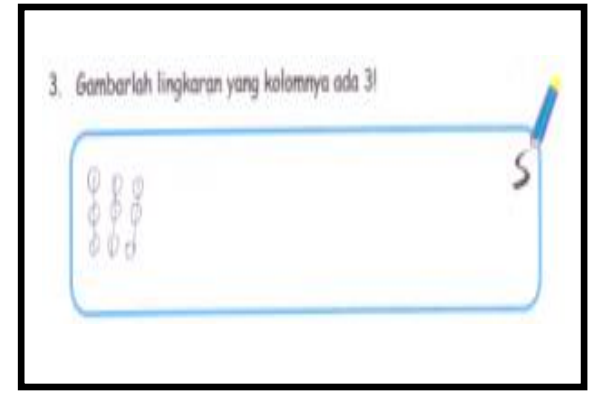

Fig. 5. Students' answer in activity 1

In Fig 5 , it can be seen that students were able to create model of circles by describing circles that the number of columns was 3 . One of the strategies of group 5 used to remember column was by outlining a circle from top to bottom.

The objective of activity 2 was how students could complete the addition of fractions with different denominators. As the problems given in this second activity, students were asked to determine the total of the mileage of row of the two countries.

On that problem, there were two fractions with different denominators. Those two fractions were the mileage of the rowing athlete, who was from Indonesia and Malaysia. On this problem, the students were already able to determine that the arithmetic operation used was the addition because the question was about the total distance. Therefore, to add two fractions, the students were required to equalize the denominator first using a set of model. In this second activity, by using the HLT that has been designed, students would 
arrange the circle based on the rules of the column, the number of the circle in each box should be the same, the number of blue circles columns represent the numerator, and the number of the whole columns represent denominator.
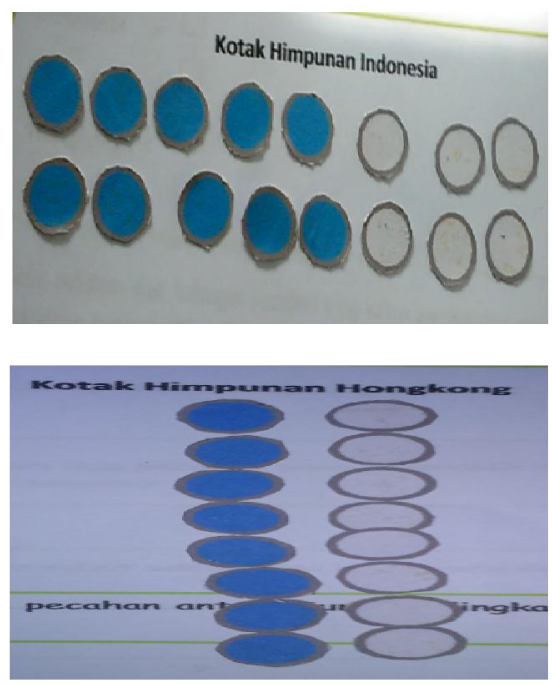

Fig. 6. Students' answer in activity 2

In Fig 6, the box set of Indonesia by the distance of athlete was $5 / 8$. Thus, the numerator was five, and the number of blue circle columns should also be 5 . Similarly, the denominator was eight, so the number of the whole columns in the box set of Indonesia was 8. Meanwhile, for the box set of Hongkong, the mileage of rowing athlete was $1 / 2$. Thus, the numerator was one, and the blue circle column should also be 1 . The denominator was two, so the total number of columns in the box set of Hong Kong was 2. For more details, it contained in the conversation transcript with group 3:

Researcher: why is the form of the box set of Indonesia like this?

Student 3: because the numerator is 5 and denominator is 8 Researcher: from this picture, which one is numerator?

Student 1: this one *pointing to the blue circle *

Researcher: What color? How many columns?

Student 3: blue, there are 5

Researcher: Which one is 8 ? What color?

Student 3: * pointing each circle column*, blue and white

Student 1: So how many columns all are there?

Student 4: 8

Researcher: Why is the box set of Hongkong like this?

Student 1: because the fractions is $1 / 2$, the blue circle is 1 column and the whole are 2 column

Researcher: what is the blue? Denominator or the numerator?

Student 2: numerator

Researcher: then how many denominators are there?

Student 5: 2
In Fig. 6, it can be seen that after the process of drafting, two fractions with the same denominator were obtained, those are $10 / 16$ and $8 / 16$. Therefore, the addition of the two fractions can be obtained which was $18 / 16$.

The objective of activity 3 was how students could complete the subtraction of fractions with different denominators. As the problems given in this second activity, students were asked to determine the difference in mileage of rowing athlete of the two countries, Tiongkok and Indonesia.

In this third activity, the students arranged the circle based on the rules of the column. The number of the circle in each box had to be the same. The number of pink circles columns represented the numerator, and the number of the whole columns represented denominator.
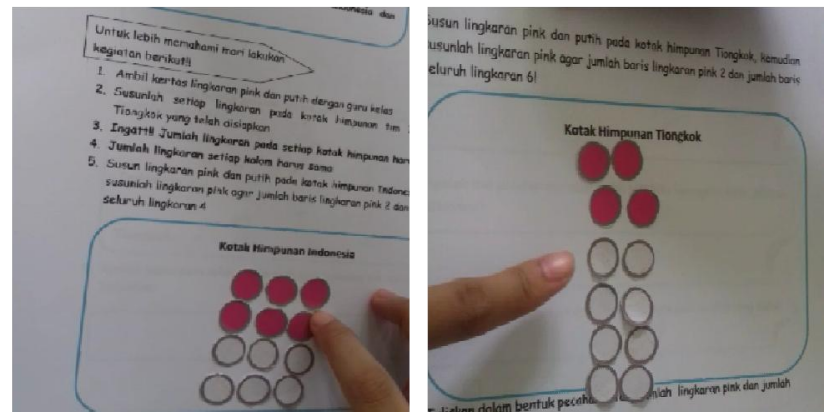

Fig. 7. Students' asnwer in activity 3

In fig.7,the box set of Indonesia by the mileage of athlete was $2 / 4$. The numerator was two, so the number of blue circle rows should also be 2 . The denominator was four, so the total number of rows in the box set of Indonesia was 4. Meanwhile, for the set box of Tiongkok, the mileage of rowing athlete was $2 / 6$. The numerator was two, so the pink circle rows must also be 2.The denominator was six, so the total number of rows in the box set of Tiongkok was 6 . For more details, it can be seen in the following conversation transcript:

Researcher: then, why is the form of the set box of Tiongkok like this? Why are the pink 2 rows and the whole 6 rows?

Student 1: because the distance of Tiongkok was

Researcher: So what does the number 2 mean in the box set?

Student 3: pink circles, there are two rows

Researcher: Which one is 6?

Student 3: * pointing each circle row*, pink and white

In Figure 5, it can be seen that after the process of drafting, two fractions with the same denominator were obtained, those were $6 / 12$ and $4 / 12$. Thus, the subtraction of two fractions can be obtained which was $2 / 12$.

\section{The Retrospective Analysis}

At this stage, HLT was used as a reference guide in answering research questions. HLT was compared to what goes on in the learning to investigate and explain how students 
can generalize from rowing activity using the model set to the addition and subtraction concepts which have the different denominator. HLT was also compared with the data obtained to describe the development of strategies used by students and the process of students' thinking in understanding the addition and subtraction of fractions concepts which have the different denominator.

A series of activities during the learning process was designed using PMRI approach. Activities which were designed aimed to produce a learning trajectory conducted in every cycle. Those were the pilot experiment and teaching experiment. In the pilot experiment, it was obtained an unpredictable new conjecture by the researchers. In the conjecture, that was set before so that it became additional to the next revision on the first activity sheet. When the researchers asked students to determine how many colors of the circle on each box set, most of the students mentioned pink and white circles. This was not by the HLT which has been designed by the researchers. The researchers hoped the answer was two since the goal was to engage students in preparing circles into the model set. Thus, the researchers made improvements on the language question so that students' answers were suitable to researcher's expectation.

Also, the other conjectures which were unpredictable by the researchers were when the researchers asked the students to write the comparison of blue circle column with the total number of columns. The students wrote a comparison of the number of the blue circle with the number of the whole circle on the model set. The objective of these questions was to guide students to arrange the circle by rows or columns of a given fraction. In the teaching experiment, the researchers conducted HLT revision so that the conjecture of students' thinking which was not suitable for the pilot experiment phase did not happen again in the teaching experiment.

Learning activities designed also reflected five characteristics of PMRI. The first characteristic is the use of Contexts for Phenomenologist exploration where learning activities begin with contextual problems frequently encountered by students as activity-based experiences.

Each activity in the learning used the problems of rowing context. The context provided in a series of activities showed that most students had to understand and know the rowing context so that it can be integrated into the learning.

The second characteristic is the use of models for mathematical concepts construction where the use of this model aims to connect students' understanding from the abstract form to the real which is commonly known as the transition from the informal to the formal form [2]. There are four levels in RME, namely situational level, referential level, general level, and formal level [2]

The third characteristic is the use of students' creation and contribution. The third characteristic is seen during the process of addition and subtraction of fractions learning from a series of activities provided. The teacher gave appreciation for the contribution of the students in the learning process in both the group and individual activities. Students were given the freedom to express and answer questions using their strategies. Learning became more meaningful and caused the variation in students' answers appearing in resolving the problem. Moreover, students who have been able to find strategies for solving problems of addition and subtraction of fractions can guide other students in the group during the discussion. It appeared in activity 1-3. Also, on each activity, the teacher plays role as a facilitator and not overly dominates learning, so students can be creative according to their understanding.

Furthermore, the fourth characteristicis students' activity and interactivity in the learning process. In the first cycle of learning, interactivity between group members does not appear due to the fact that students in the pilot experiment never followed the learning using the teaching method of discussion, so it is difficult for them to cooperate with the other members of their group. Meanwhile, on the second cycle, the interactivity among students and between teachers and students appeared on every activity both in discussions and individuals. Students in this teaching experiment were very cooperative so that learning could run smoothly.

In the implementation of instructional design, there are some social norms prevailing in the classroom during the learning process, as students discussed in groups and asked the members of the group when they did not understand the meaning of the questions. It was also with the interaction between teacher and students; the teacher asked students about solving strategies used in solving the problems given, the teacher guided students to ask/argue during class discussion. So, it can be said that the implementation of math learning used PMRI approach and the rowing context can bring social norms in the classroom. It was in accordance with the [14] who state that teachers are aware that they had been using some of the activities, including the social norm in the class like guiding students to question and argue. By discussions and interviews, the researchers and teacher tried as much as possible to strive for social norms during the learning process.

\section{CONCLUSION}

Based on the results and discussion that have been described previously, it can be concluded that the application of HLT in this study is a learning trajectory that could help students in learning percentage by using the dayung/rowing context. The elements in the trajectory of learning in this study help students as follows:

a. Experience in meaningful learning and fun activities in which students are asked to write down fractions from a problem related to mileage of rowing from start to finish because the mileage of rowing in the certain time can present units of the whole by the definition of fractions.

b. To add two fractions, students use a set of model. Students were asked to arrange the circles consisting of two colors arranged based on the rule of rows and columns. In LAS 1, the circle consisted of blue and white with the rules of the column, while LAS 2 consisted of pink and white circle with the rule of row. The fractions which are summed are arranged with the rules of column by the number of blue circles column representing the numerator and the number of circles representing denominator. The number of circles between the two fractions must be the same.

Thus, learning trajectory which has been implemented in this study is one of a positive contribution to the development 
of the Local Instructional Theory (LIT) in learning fraction by set of models in the context of rowing/dayung.

\section{ACKNOWLEDGMENT}

The researchers express their gratitude to Direktorat Jendral Pendidikan Tinggi Indonesia who has funded a post grant research in 2017. Then, the researchers would like to thank to Universitas Negeri Makassar, which provides an opportunity to present and publish the results of this study.

\section{REFERENCES}

[1] Zulkardi, The "P" in PMRI: Progress and Problems, ICMA Mathematic, 2009.

[2] K. Gravemeijer, Developing Realistic Mathematics Education, Utrecht CD-b Press, The Netherlands, 1994.

[3] R. Soedjadi, "Inti dasar-dasar pendidikan matematika realistik Indonesia," Jurnal Pendidikan Matematika 1(2), 2007, pp.1-10.

[4] R. I. I. Putri, "Pembelajaran materi bangun datar melalui cerita menggunakan Pendekatan Matematika Realistik Indonesia (PMRI) di Sekolah Dasar," Jurnal Pendidikan dan Pembelajaran, 18(2), 2011, Retrieved from http://journal.um.ac.id/

[5] Bustang, Zulkardi, Darmawijoyo, M. Dolk, \& D. Van Eerde, 2013 "Developing a local instruction theory for learning the concept of angle through visual field activities and spatial representations," International Education Studies, 6(8), Yogyakarta: IndoMS, 2013, pp.58-70.
[6] L. Kennedy, Guiding Children's Learning of Mathematics, California: Wardsworth Publishing Company, 1994.

[7] E. Mamede, Issues On Children's Ideas of Fraction when Quotient Interpretation is Used, 2010, pp.1-10.

[8] D. Haris, \& R. I. I. Putri, "Design research in pmri: third graders' preliminary of teaching and learning about area measurement through traditional handicraft," Makalah dipresentasikan di Seminar Internasional di Universitas Riau, Pekanbaru, 11 November 2010. [Online].

http://math.unri.ac.id/index.php?option=com_content\&task=view\&id=8 $04 \&$ Itemid $=67$.

[9] J. A. Van den Walle, K. S. Karp, \& J. M. Bay-Williams, Elementary and Middle School Mathematics Teaching Developmentally (Eight ed.), United States of America: Pearson Educations, 2013.

[10] T. Plomp, \& N. Nieveen, Educational Design Research: an Introduction In Plomp, T., \& Nieveen, N. (Editor), An Introduction To Educational Design Research, Enschede: slo, 2007, pp.9-35.

[11] K. Gravemeijer, \& D. Van Eerde, "Research as a means for building a knowledge base for teaching in mathematics education," The Elementary School Journal.109(5), 2009, pp.510-524.

[12] K. Gravemeijer, \& P. Cobb, Design Research From A Learning Design Perspective, In Akker, dkk. (Ed.): Educational Design Research. New York: Routledge, 2006, pp.17-51.

[13] N. S. Sumarto, F. Van Galen, Zulkardi, \& Darmawijoyo, Proportional reasoning: how do the 4 th graders use their intuitive understanding? International Education Studies, 1(7), 2014, pp.69-80.

[14] R. I. I. Putri, M. Dolk, Zulkardi, Professional development of PMRI teachers for introducing social norms, IndoMs-JMe: (6), 2015, pp.1 15. 